\title{
IMPLANTAÇÃO DO PROJETO ROBÓTICA EDUCACIONAL
}

\section{ARTIGO ORIGINAL}

JESUS, André Luis Neris de ${ }^{1}$

JESUS, André Luis Neris de. Implantação do projeto robótica educacional. Revista Científica Multidisciplinar Núcleo do Conhecimento. Ano. 06, Ed. 12, Vol. 04, pp. 75-85. Dezembro de 2021. ISSN: 2448-0959, Link de acesso: https://www.nucleodoconhecimento.com.br/educacao/projeto-robotica-educacional, DOI: 10.32749/nucleodoconhecimento.com.br/educacao/projeto-roboticaeducacional

\section{RESUMO}

O presente artigo tem como objetivo explicitar as experiências no contexto da robótica e tecer um diálogo entre a robótica e à docência com ações educativas voluntárias para o ensino a alunos de classes menos favorecidas, realizadas do ano de 2017. O projeto teve como objetivo geral solidificar uma aprendizagem teóricoprática e proporcionar aos alunos meios tecnológicos compatíveis ao desenvolvimento histórico atual, além de despertar o espírito da criatividade e da engenhosidade aos futuros profissionais. Outro objetivo, é colocar os alunos em contato com as regras básicas da linguagem de programação, instrumentalizá-los ao universo da eletrônica possibilitando a análise e montagem de circuitos eletrônicos. O intuito das vivências em robótica é fazer com que o aluno aprenda a utilizar a tecnologia Arduino nos seus aspectos teórico e práticos para montagem de dispositivos robóticos, utilizando-se a metodologia ativa. Neste contexto, o presente estudo, tem como questão norteadora: é possível ministrar um curso de robótica em escolas públicas e em função disso obter resultados positivos? Para responder este

\footnotetext{
${ }^{1}$ Mestrado Profissional em Matemática pela Universidade Federal do Vale do São Francisco (UNIVASF), Especialização Lato Sensu em Mídias na Educação, na Universidade Estadual do Sudoeste da Bahia (UESB); Licenciatura em Matemática pela Universidade Federal da Bahia - UFBA; Bacharelado em Análise de Sistemas pela Universidade do Estado da Bahia - UNEB; ORCID: https://orcid.org/0000-0003-1376-7107.
}

RC: 103074

Disponível em: https://www.nucleodoconhecimento.com.br/educacao/projetorobotica-educaciona 
questionamento, será relatado sobre um percurso pedagógico tecnológico realizado no Colégio Estadual Sete de Setembro, escola pública localizada no Bairro de Paripe, subúrbio ferroviário de Salvador - BA. Durante o desenvolvimento do projeto, foi possível perceber que os alunos conseguem ter relevância em seus trabalhos, expondo-os em feiras e mostras, tanto locais como nacionais. Sendo assim conceituou-se as áreas de análise, robótica, educação e docência e definiu-se linguagens de programação e eletrônicas, como as ações centrais do projeto. Os resultados desenvolvidos no projeto culminaram em exposições nas Feiras e Mostras nacionais.

Palavras-chave: Educação, robótica, Arduino, metodologia ativa.

\section{INTRODUÇÃO}

O presente artigo propõe a explanação de um percurso pedagógico tecnológico a partir do ano de 2017, no Colégio Estadual Sete de Setembro, escola pública localizada no Bairro de Paripe, subúrbio ferroviário de Salvador - Ba. Trata-se de uma ação voluntária deste professor, que contou com a autorização da gestão da unidade de ensino, por intermédio de seu diretor, o qual cedeu as dependências da escola para a implementação do projeto.

O objetivo geral do projeto foi solidificar uma aprendizagem teórico-prática e proporcionar aos alunos meios tecnológicos compatíveis ao desenvolvimento histórico atual, além de despertar o espírito da criatividade e da engenhosidade aos futuros profissionais. Outro objetivo, era colocar os alunos em contato com as regras básicas da linguagem de programação, instrumentalizá-los ao universo da eletrônica possibilitando a análise e montagem de circuitos eletrônicos.

Tendo em vista a importância de ações como estas, convém definir e explicitar os termos como voluntariado na ação educativa, bem como seus conteúdos e a metodologia utilizada. O principal intuito das vivências em robótica é fazer com que 0 aluno aprenda a utilizar a tecnologia Arduino nos seus aspectos teórico e práticos 
para montagem de dispositivos robóticos, utilizando-se a metodologia ativa. Neste contexto, levantou-se a seguinte questão norteadora: é possível ministrar um curso de robótica em escolas públicas e em função disso obter resultados positivos?

Pelo fato de a temática não fazer parte do currículo das escolas públicas da Bahia e aliado a um desejo dessa clientela de participar de cursos voltados para área de tecnologia, deparamo-nos com o fator econômico como empecilho para esta formação educacional, inviabilizando a participação destes estudantes. Diante de tal situação, oportunizar o projeto de robótica foi a melhor perspectiva encontrada como trabalho voluntário.

Nesse cenário, o fator tempo de descanso é deixado, muitas vezes de lado, para que seja possível a participação nesses cursos, os quais ocorrem no intervalo das aulas entre o turno vespertino e noturno, além dos investimentos com a aquisição de kits de robótica Arduino, sensores e componentes eletrônicos, os quais são feitos com muita satisfação, pois é extremante gratificante perceber a felicidade de seu alunado em participar de tal projeto.

A definição de robótica na educação bem como das inovações que essa temática repercute na formação dos discentes mostram um entrelaçamento de ideias nas quais culmina na participação em eventos, momento no qual é possível demonstrar as produções dos alunos em Feiras e Mostras na cidade de Salvador - BA, com abrangência no estado da Bahia e nacional.

\section{DOCÊNCIA E VOLUNTARIADO: ARTICULAÇÕES TEÓRICAS}

A fim de conceituar as ações voluntárias, ou seja, voluntariado, termo tão utilizado atualmente, define-se termos como solidariedade, cidadania, autotransformação, transformação social, desejo de ser útil e de sentir-se importante, os quais representam, conforme coloca Lovato (1996), fatores determinantes ligados ao ser voluntário.

RC: 103074

Disponível em: https://www.nucleodoconhecimento.com.br/educacao/projetorobotica-educaciona 
Nesta análise do sentido de voluntariado, Drucker (1997) contribui ao mencionar o ideal ou a missão, bem como sua importância de valor social como elementos fundamentais desse tipo de trabalho. A definição das Nações Unidas versa que

o voluntário é o jovem ou adulto que, devido a seu interesse pessoal e seu espírito cívico, dedica parte do seu tempo, sem remuneração alguma, a diversas formas de atividade, organizadas ou não, de bem-estar social ou outros campos (CORULLÓN, 2002, p. 141).

A motivação para iniciar o trabalho voluntário de robótica educacional na Escola Estadual Sete de Setembro, já mencionada anteriormente, está vinculada à formação acadêmica em Tecnologia e Educação, área de atuação deste pesquisador por pelo menos 20 anos.

\subsection{A ROBÓTICA EDUCACIONAL}

À guisa de definir conceitos, nesse ponto torna-se necessária a compreensão da relação entre robótica e a educação. De acordo com Débora Noemi, robótica faz com que os alunos tenham uma maior proximidade com a ciência e a tecnologia, áreas do conhecimento que geram grande interesse nos estudantes. Entende-se que a programação de robôs traz uma série de benefícios para a qualidade do ensino. (NOEMI, 2021)

O termo Robótica Educacional ou Pedagógica, pode ser entendida por ambientes de aprendizagem com o uso de materiais de sucata ou kits de montagem compostos por peças diversas, motores e sensores controláveis por computador e softwares que permitam programar o funcionamento dos modelos montados. (DIEB, 2021)

A Robótica Educacional define-se, segundo Lopes (2008) como um conjunto de recursos que visa o aprendizado científico e tecnológico integrado às demais áreas do conhecimento, utilizando-se de atividades como design, construção e programação de robôs. (LOPES, 2008, p. 46)

O termo Robótica Educativa é usado por Maisonnette (2002) para definir o controle de mecanismos eletroeletrônicos através de um computador, transformando-o em

RC: 103074

Disponível em: https://www.nucleodoconhecimento.com.br/educacao/projetorobotica-educaciona 
uma máquina capaz de interagir com o meio ambiente e executar ações definidas por um programa criado pelo programador a partir destas interações.

É a partir desse entrelaçamento de definições da robótica educacional que o projeto é pautado, mantendo uma perspectiva de possibilitar aos alunos um ambiente de aprendizado com uso de tecnologia, em particular com o Arduino, com objetivo de desenvolver projetos de maneira multidisciplinar de modo a suscitar no aluno o espírito investigativo através de uma metodologia ativa na construção do conhecimento.

\subsection{DOCÊNCIA E AÇÕES EDUCATIVAS}

O primeiro ano do curso foi oferecido apenas para alunos do $6^{\circ}$ ano do Ensino Fundamental. Em vista da grande procura e da limitação de vagas houve a necessidade de realizar uma prova de seleção para os interessados.

Diante do sucesso do projeto, já em andamento, e com ações estruturadas, passouse a ofertar o curso para os demais segmentos do Ensino Fundamental II e Ensino Médio. As aulas de robótica são ministradas no período vespertino após o último horário das aulas regulares da escola. Dessa forma, os participantes do curso permanecem na escola para as aulas de robótica que acontecem duas vezes por semana das $17 \mathrm{~h} 40$ min às 19 horas durante todo o período do ano letivo. O projeto tomou grande dimensão na escola, tanto que a partir de 2018 foi preciso disponibilizar mais horários para as turmas e dessa forma estruturou-se duas turmas, uma turma às segundas e quartas e a outra turma às terças e quintas.

O projeto de robótica educacional é baseado na inovação, e principalmente, no resgate pelo desejo de aprender e está vinculado a um dos segmentos tecnológicos que mais crescem em nossa sociedade: a robótica, representando a sinergia de diversas áreas do conhecimento, como, por exemplo, a eletrônica, a física, a biologia, os sistemas de controle e a informática (SASAHARA; CRUZ, 2007). Apesar desse viés multidisciplinar da robótica e de seu uso como elemento 
motivador para ensino-aprendizado, ela é pouco utilizada nas instituições de ensino pública. Essas perspectivas corroboram com o pensamento de Moraes (2010) quando diz que a robótica educacional pode ser esta o elo entre a teoria e a prática, de modo a construir uma ponte sólida entre a aprendizagem clássica e a moderna.

Neste contexto, convém ressaltar o conteúdo do curso. As aulas do projeto de Robótica possuem um caráter teórico-prático, sendo abordados os aspectos teóricos de um determinado assunto e em seguida realizados experimentos práticos. A estrutura possui 4 eixos de formação:

Quadro 1 - Áreas de estudo e conteúdos do curso de robótica educacional

\section{ÁREA DE ESTUDO CONTEÚDOS \\ ELETRÔNICA Conceitos elétrico; componentes eletrônicos; motores elétricos, sensores e projeto de circuitos simples com a protoboard. \\ Lógica de Programação, Algoritmos em pseudocódigo e \\ LINGUAGEM DE PROGRAMAÇÃO Implementações de Códigos em Linguagem C, que é a base para programar o microcontrolador da plataforma Arduino. Introdução a programação com Arduino; componentes de um programa: criação de variáveis, comandos de seleção e repetição, modularização.}

ARDUINO

Plataforma livre e de baixo custo. Arduino é um minicomputador capaz de processar informações de entradas e saídas entre outros dispositivos ou componentes. Conceitos de microcontroladores; introdução à placa de prototipação Arduino; portas de entrada e saída; portas analógicas e digitais; projetos de circuitos microcontrolados. Através das integrações dos três eixos anteriores o curso possibilita aos alunos desenvolver braços robóticos e

RC: 103074

Disponível em: https://www.nucleodoconhecimento.com.br/educacao/projetorobotica-educaciona 
ROBÓTICA

carrinhos robôs, aprendendo desde a montagem mecânica, a criação dos circuitos e a programação da plataforma Arduino, tudo isso passo a passo e de maneira fácil e profissional.

Fonte: Autoria própria

\section{METODOLOGIA}

A Metodologia de ensino é considerada como um procedimento didático para facilitar o processo de aprendizagem. Já a metodologia ativa, é um processo amplo e possui como principal característica a inserção do aluno/estudante como agente principal responsável pela sua aprendizagem, comprometendo-se com seu aprendizado.

Lima (2016) define que

as metodologias ativas promovem pró-atividade, comprometimento no processo educacional e vinculação da aprendizagem aos aspectos significativos da realidade. A robótica educacional entra nesta perspectiva como um instrumento a ser utilizado em promoção de um processo de aprendizagem dinâmico e ativo. (LIMA, 2016, p. 421)

No projeto de Robótica Educativa o professor utiliza-se da metodologia ativa, pois os temas abordados durante o curso, sobretudo os conteúdos de linguagem de programação, análise e montagem de circuitos elétricos e as montagens e testes dos dispositivos robóticos exigem por parte dos alunos e professores uma postura, que é oposta às metodologias na qual o aluno participa das aulas como mero expectador e não interage de maneira significativa no processo de ensino aprendizado.

Camargo e Daros (2018) afirmam que:

as metodologias ativas são um conjunto de atividades organizadas, com a presença marcante da intencionalidade educativa. Os estudantes deixam de ser agentes passivos (que apenas escuta) e passam a ser membros ativos no processo de aprendizagem por meio de estratégias pedagógicas que estimulam a apropriação, a

RC: 103074

Disponível em: https://www.nucleodoconhecimento.com.br/educacao/projetorobotica-educaciona 
produção do conhecimento e a análise de problemas. (CAMARGO e DAROS, 2018)

No entanto, na metodologia ativa o aluno torna-se protagonista no processo de construção de seu conhecimento, sendo responsável pela sua trajetória e pelo alcance de seus objetivos, no qual deve ser capaz de autogerenciar seu processo de formação com ou sem intermediação do professor.

\section{ATIVIDADES DESENVOLVIDAS}

De forma a explicitar as ações desenvolvidas durante o Projeto de Robótica, o quadro a seguir demonstra a implantação das ações junto aos discentes que participaram do projeto no Colégio Estadual Sete de Setembro.

Quadro 2 - Implantação das ações do projeto de robótica

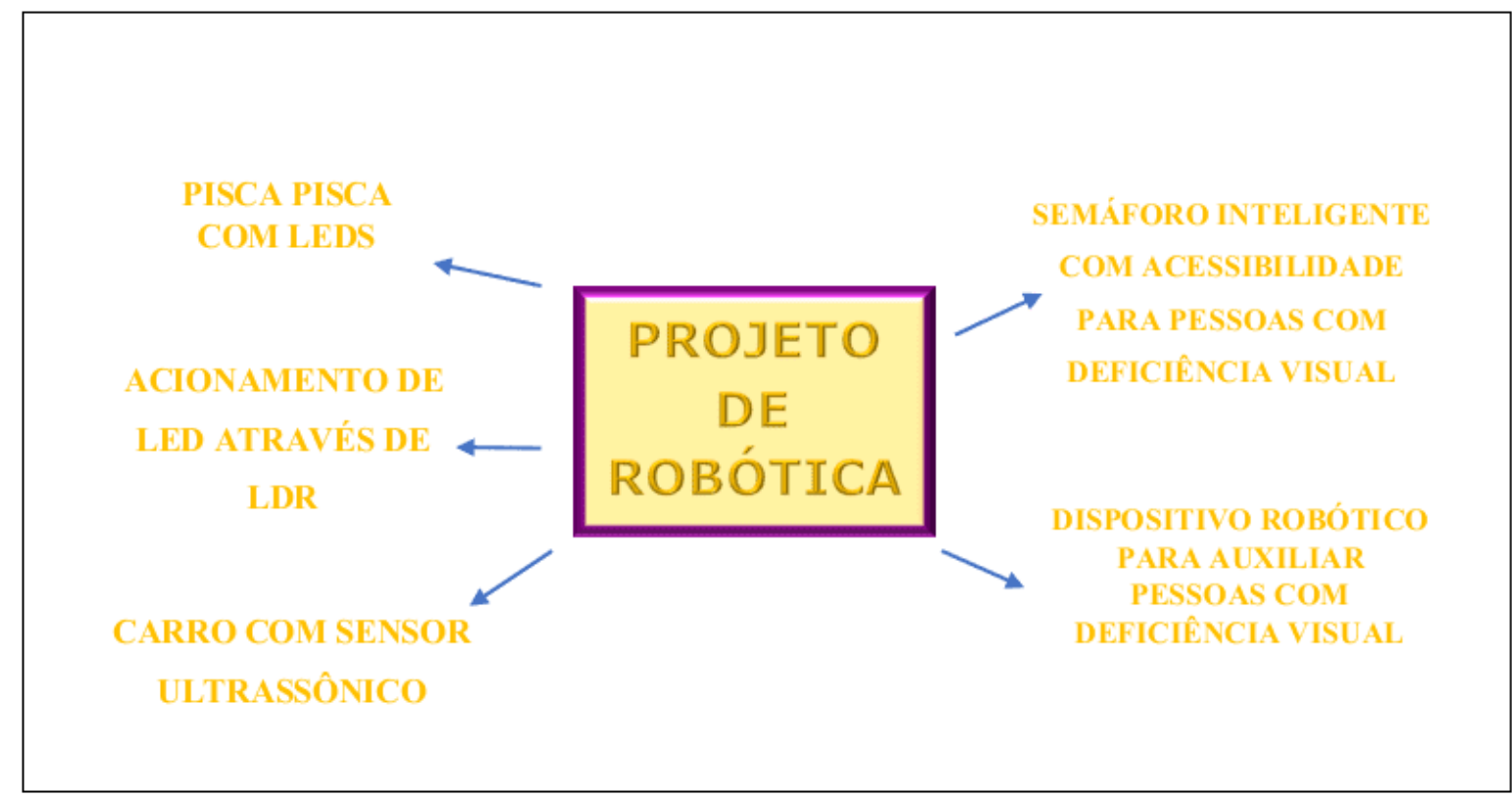

Fonte: Autoria própria

\section{PARTICIPAÇÃO EM EVENTOS}

O Projeto de Robótica participou de uma feira - FECIBA, e nessa ocasião foi possível expor e realizar trocas culturais, tanto entre as escolas participantes, como

RC: 103074

Disponível em: https://www.nucleodoconhecimento.com.br/educacao/projetorobotica-educaciona 
participar da competição entre as experiências, as quais foram orientadas pelos docentes para estimular a criação e a estruturação da pesquisa científica na Educação Básica, conforme versa o site do evento.

Um ponto a ser explicitado é que além da competição, a estratégia do ensino deve se pautar na cooperação. $O$ interesse é também estimular a cooperação para o fortalecimento de uma rede de pesquisadores juniores e seus orientadores. (FECIBA, 2020)

A MNR - Mostra Nacional de Robótica é uma mostra científica que busca estimular o estudo e a pesquisa na área da Robótica. É voltada para alunos do Ensino fundamental, Médio, Técnico e alunos de Graduação, pós-graduação ou pesquisadores da área. (MNR, 2015)

Os objetivos da Mostra visam a promoção e a valorização interdisciplinar, colaborativa, investigativa e com foco na experimentação e inovação; além de estimular os jovens às carreiras científico-tecnológicas, valorizando os trabalhos por eles desenvolvidos, de forma a gerar melhores condições para seu aprimoramento técnico e pessoal, como definido pelo site do evento. (MNR, 2015)

Unir os jovens num mesmo propósito proporciona essa troca e aprimoramento de novos projetos, com ideias e tecnologias que serão vindouras.

A Mostra tem, portanto, esse intuito, de divulgar a ciência e a tecnologia junto a sociedade brasileira, principalmente os avanços tecnológicos e científicos na área de Robótica, Automação e Engenharia.

Tanto na Feira como na Mostra, os alunos participaram com o projeto dispositivo Robótico para Auxiliar a Pessoa com Deficiência Visual, cujo objetivo foi desenvolver um protótipo robótico, com tecnologia Arduino, que possibilite ao deficiente visual ter um deslocamento de maneira autônoma e sem a utilização de bengala, a fim de lhe proporcionar qualidade de vida.

RC: 103074

Disponível em: https://www.nucleodoconhecimento.com.br/educacao/projetorobotica-educaciona 


\section{RESULTADOS}

Os alunos perceberam que a bengala utilizada pelo deficiente visual tem certa limitação, como exemplo, não conseguir detectar obstáculos acima da altura da cintura, o que pode provocar acidentes. E como uma alternativa a esse empecilho, eles propuseram implementar um dispositivo robótico, com tecnologia Arduino, que possibilitasse ao deficiente visual uma maior autonomia para o deslocamento nas ruas de maneira segura.

Para tanto, os alunos tiveram que, antes da implementação do projeto, passar por dois eixos de formação, sendo eles: estudar os princípios teóricos e práticos da eletrônica tais como circuito elétrico; componentes eletrônicos; protoboard; motores elétricos e tipos de motores (de corrente contínua, de passo e servomotor); sensores (infravermelho, luz, temperatura e ultrassom).

Em paralelo, realiza-se a capacitação para desenvolver programas utilizando a linguagem de programação $\mathrm{C} / \mathrm{C}++$. Diante desta linguagem, foram trabalhados os principais conceitos da área da programação tais como variável, tipo de dado, operador, função e estruturas de controle.

Depois destes aprofundamentos teóricos nesta fase, passamos a implementar pequenos projetos de robótica tais como: semáforos inteligentes e trabalhos envolvendo os mais variados sensores e dispositivos da eletrônica e Arduino.

Depois dessa imersão teórica e prática da tecnologia Arduino, é que passamos a construir, programar e testar o dispositivo robótico. No entanto, diante da complexidade do projeto foi sugerido pelos alunos, novas implementações para tornar o dispositivo dotado de mais recursos e sensores, permitindo ao deficiente visual uma maior autonomia para seu ir e vir e consequentemente melhorar sua qualidade de vida. 


\section{CONSIDERAÇÕES FINAIS}

A utilização da robótica educacional possibilitou que os alunos relacionassem a teoria com a prática e, portanto, vivenciar o conhecimento de uma forma mais concreta, com uma maior efetividade no processo de ensino-aprendizagem.

Nessa proposta, o estudante encontra na prática pedagógica com a robótica educacional com tecnologia Arduino, uma forma de entender os conceitos que antes pareciam abstratos, e assimilá-los de modo mais prático. Isso ocorre porque os estudantes tornam-se protagonistas do processo de aprendizagem, percepção esta reforçada pela teoria construcionista de Papert (2008), ao considerar que cada um se torna responsável por sua aprendizagem à medida que constrói algo novo.

O ensino de robótica possibilita ao aluno interagir com diferentes estruturas, operando sobre o concreto, agindo, explorando, olhando, experimentando, atribuindo significado, testando suas hipóteses e finalmente, tirando conclusões. Essa concepção está fortemente ligada à metodologia ativa utilizada, pois os alunos são induzidos a construir e programar robôs, e dessa forma colocam em prática todo um arsenal teórico de conhecimento para concretizar a montagem de um dispositivo robótico.

Portanto, respondendo a questão norteadora: é possível ministrar um curso de robótica em escolas públicas e em função disso obter resultados positivos? Concluise que é possível obter resultados positivos com o ensino de robótica para os alunos de escola pública, tendo em vista que o resultado final, os dispositivos elaborados foram concluídos, funcionam a contento e foram apresentados nas mostras mais relevantes em robótica a nível nacional, com relevância social de auxílio e melhoria de qualidade de vida.

Ao final deste processo, compreende-se que em todo tempo se aprende, e novos projetos serão cada vez mais de extrema significância para futuras inovações tecnológicas. 


\section{REFERÊNCIAS}

CAMARGO, Fausto; DAROS, Thuinie Medeiros Vilela. A sala de aula inovadora: 9 estratégias pedagógicas para o aprendizado ativo. Porto Alegre: Penso, 2018.

CORULLÓN, Mónica Beatriz Galiano. Voluntariado na empresa: gestão eficiente da participação cidadã. São Paulo: Peirópolis, 2002.

DRUCKER, Peter. Administração de organizações sem fins lucrativos. São Paulo: Pioneira, 1997.

FEIRA de Ciências da Bahia - FECIBA. In: Governo do Estado. Estudantes educação. Disponível em:<http://estudantes.educacao.ba.gov.br/feciba> Acesso em: 12 nov. 2021.

FEIRA de Ciências da Bahia - FECIBA. Progestão: Programa de Capacitação de gestores. c2013. Disponível em: <https://cevogba.blogspot.com/2014/05/programaciencia-na-escola-iv-feciba> Acesso em: 12 nov. 2021.

LIMA, Valéria Vernaschi. Espiral construtivista: uma metodologia ativa de ensino-aprendizagem. Interface-Comunicação, Saúde, Educação, v. 21, p. 421434, 2016.

LOPES, Daniel de Queiroz. A exploração de modelos e os níveis de abstração nas construções criativas com robótica educacional. 2008. 326f. Tese de Doutorado em Informática na Educação - CINED, Universidade Federal do Rio Grande do Sul, Porto Alegre, 2008.

LOVATO, Flora. Voluntário, sinônimo de participação? Grandes empresas investindo no desenvolvimento social. São Paulo: AIESEC-FGV, 1996.

MAISONNETTE, Roger. A utilização dos recursos informatizados a partir de uma relação inventiva com a máquina: a robótica educativa. In: Proinfo - 
Programa Nacional de Informática na Educação - Paraná. Disponível em: <www.proinfo.gov.br>. Acesso em: 15 jun. 2002.

METODOLOGIAS ativas. In: WIKIPÉDIA: a enciclopédia livre. Wikipedia, 2006. Disponível em <https://pt.wikipedia.org/wiki/Metodologia_ativa > Acesso em: 07 nov. 2021.

METODOLOGIAS ativas. In: BLOG LYCEUM: Conhecimento Desenvolvendo a Educação. Disponível em: <https://blog.lyceum.com.br/metodologias-ativas-deaprendizagem/>Acesso em: 07 nov. 2021.

MORAES, M. C. Robótica Educacional: socializando e produzindo conhecimentos matemáticos. 2010, 144f. Dissertação de Mestrado Programa de Pós-Graduação Educação em Ciências) - Universidade Federal do Rio Grande, FURG, 2010. Disponível em: $<$ https://periodicos.ifpb.edu.br/index.php/praxis/article/download/1425/641> Acesso em: 21 out. 2021.

MOSTRA Nacional de Robótica - MNR: Uma iniciativa pública, gratuita e sem fins lucrativos. O que é a MNR? 2021. Disponível em: <http://www.mnr.org.br/anais/> Acesso em 12 nov. c2021.

NOEMI, Débora. A importância da robótica na rotina de aprendizagem. Escolas Disruptivas. São Paulo. 24 mai. 2019. Disponível em: <https:// https://escolasdisruptivas.com.br/steam/robotica/>. Acesso em: 23 out. 2021.

PAPERT, S. A máquina das crianças: repensando a escola na era da informática. Ed. Rev. Porto Alegre: Artmed, 2008.

ROBÓTICA EDUCACIONAL. In: Dicionário interativo da educação brasileira. Agência Educa Brasil. Disponível em: https://www.educabrasil.com.br/roboticaeducacional/. Acesso em: 23 out. 2021.

RC: 103074

Disponível em: https://www.nucleodoconhecimento.com.br/educacao/projetorobotica-educaciona 
SASAHARA, L. R.; CRUZ, S. M. Hajime. Uma nova abordagem em robótica educacional. In: CONGRESSO DA SBPC, p. 27, 2007, Rio de Janeiro. Anais. Rio de Janeiro, 1242007. em: $<$ https://periodicos.ifpb.edu.br/index.php/praxis/article/download/1425/641> Acesso em: 21 out. 2021.

Enviado: Novembro, 2021.

Aprovado: Dezembro, 2021. 